\title{
Electronic Delivery
}

Sylwester Szczepanik, Michat Tabor

\section{Introduction}

The exchange of letters, documents and their service is one of the basic activities of the legal profession, regardless of the time and legal system in which he has to practice. Also in times of strong development of technology and its impact on the legal profession, the indicated aspect of activity is subject to significant changes. In the case of traditional correspondence exchange, the main role of the lawyer was limited to choosing two possible methods of exchange:

1) using an intermediary in the form of a postal operator;

2) the implementation of delivery with own human resources (including each other).

If a postal operator was selected, it was necessary to ensure that the parcel with correspondence was properly secured, the addressee was correctly identified and the payment was made. An additional element was a risk analysis consisting in assessing whether a given item of correspondence is to be a registered item, registered item with return confirmation of receipt or a regular item.

In the case of the exchange of own human resources, the same challenges arose as in the case of a postal shipment, with the exception of making a payment and selecting the shipment variant.

The choice of a given method was mainly determined by such elements as the time of delivery, the probability of receiving the parcel by the other party and possibly a legal provision that could provide for a better legal position for a given method of shipment (the procedural deadline).

The difference in the indicated methods, which certainly occurs and is often not taken into account, is the issue of the need to protect the parcel against loss and damage and the responsibility for any loss or damage to the parcel.

When new technologies are used, the range of steps required to select the final delivery method is much greater. Due to the development of technology, even the traditionally understood postal item may have a 
hybrid character, i.e. at some stage of the delivery process it may change its form from paper to electronic (or vice versa). The situation is further complicated when methods of correspondence exchange not regulated by generally applicable law are used. The challenges include such issues as: parcel security, identification of addressees, place of exchange.

\section{Correspondence Exchange - Terminological Remarks}

Later in the chapter, the term "correspondence" will be used to describe the above-mentioned phenomena in general. It should be noted that this term will be used autonomously in this chapter. This term will mean the transmission of information, in particular of documents, between two lawyers, irrespective of the type of tool used to provide such information or documents, be it in paper or electronic form. In the authors' opinion, the indicated understanding of this concept is broad and, at the same time, adequate enough to highlight important elements, such as:

1) the act of exchange;

2) document - as information;

3) intention of this activity;

4) tool independence;

5) two-sided actions.

We can divide correspondence into two types, i.e. horizontal exchange, carried out between lawyers, and hierarchical exchange, carried out between lawyers and authorities (including public administration bodies or courts). In the traditional model of division into public and private law, it can be concluded that horizontal exchange is the domain of private law, and hierarchical exchange is the domain of public law. Of course, this division is not consistent, because in the case of, for example, court procedures, requiring lawyers who are parties' attorneys to exchange letters between them as a formal condition, accept a given letter by the court, such exchange, although it took place horizontally, is carried out under the rule of law. public.

The presented division into both horizontal and hierarchical exchange as well as further indication of the elements of public and private law will be arranged later in the chapter. However, issues related to technological solutions as well as online dissertations and tools for remote work remain outside the scope of the chapter. These issues are discussed in greater detail in other parts of the monograph, in particular devoted to cloud computing services and the use of tools LegalTech in the judiciary, law 
enforcement agencies and law firms. It can only signal that Technological solutions are currently based mainly on cloud computing services, with the help of which work on shared computing resources or exchange of correspondence is carried out by placing files by one user in the area separated for other - indicated by him - users for sharing. The above should be distinguished from a situation where placing a file in such a separated sphere only facilitates the transmission of correspondence, and the legal effects are related to the moment of granting this access.

\section{Example:}

An example of such a service is the transmission by electronic means, e.g. by e-mail, of information about the possibility of reading the content of documents which, due to the large size of the files, have been made available to the other party with the option of saving them to another location by the other party. Such an e-mail has an informational value only and allows you to find access to the resource. Another example of such sharing is document collaboration.

\section{Horizontal Exchange of Correspondence}

In the case of the legal profession, the exchange of correspondence is not left outside the scope of the law. Requirements regarding cybersecurity and data protection, including professional secrecy, should be indicated here. This is due to the fact that lawyers are bound by legal provisions regulating the status and manner of practicing the profession, and often by corporate rules ${ }^{1}$. Two basic principles emerge in the foreground, which are:

1) the principle of professional secrecy;

2) the principle of the good of the client.

Within the framework of horizontal exchange, we can distinguish two basic types of this exchange. The first type is the exchange of actual correspondence, the second is the exchange of legal correspondence. In the first case, it concerns the exchange of professional correspondence, however, the fact of exchanging correspondence has no legal consequences, but

1 See Dariusz. Szostek (ed), Bezpieczeństwo danych i IT w kancelarii prawnej radcowskiej/adwokackiej/notarialnej/komorniczej. Czyli jak bezpiecznie przechowywać dane w kancelarii prawnej (C. H. Beck 2018). 
only a change of the facts. In the second case, the main purpose of the exchange of correspondence is to perform a legal act, exercise a right or legal obligation towards the other party or with effect on the third party. In the Polish doctrine of legal theory, this type of exchange may be treated as a conventional activity ${ }^{2}$. Both types of exchanges can only take place between lawyers or between lawyers and clients. However, regardless of whether the correspondence is exchanged in the actual or legal sphere, the lawyer who performs the exchange should always take into account the principle of professional secrecy and the principle of the client's welfare.

Even a cursory analysis shows that problematic from the point of view of the above-mentioned exchange of correspondence becomes the rule:

1) by tools not examined by the lawyer;

2) in an unsecured manner;

3) in a manner that does not provide an acceptable degree of certainty in the identification of the other party.

Easy and cheap access to technology makes it tempting to use even free communication exchange tools. An example of such action may be social mediawhich provide functionalities of information exchange between selected participants of a given medium. The use of these tools to exchange professional correspondence, without checking the rules of operation of a given tool, the scope of information collected by the owner of the tool, the method of transferring this information and technical security measures, may easily lead to breach of the principle of professional secrecy. A similar problem concerns the use of public e-mail accounts. Although the information transmission technology differs from the above-mentioned for example, there is still the problem of keeping the two rules above.

Of course, the entry into force of the GDPR also affected lawyers. Not only industry law and corporate rules, but also the provisions of the GDPR, threatened with high sanctions, have strengthened the attorneys' care in the selection of correspondence exchange, e.g. by continuing to use free and generally available solutions to exchange correspondence, the content itself is adequately secured (e.g. by encrypting).

Ensuring the security of the exchange of correspondence for horizontal activities is only one of the elements of the issue. The second element is the correct identification of the addressee of the correspondence. In the case of

2 For more on conventional acts see Stanisław Czepita 'On the Concept of a Conventional Act and its Varieties' (2017) Year LXXIX No. 1 Legal, Economic and Sociological Movement 85 . 
exchanging correspondence in electronic form, the most commonly used model today is the use of e-mail devices. In this model, data is sent to the other party's e-mail address:

1) indicated in the document being the source of the obligation, e.g. contract, party's notifications about the e-mail address, invoice, etc.;

2 ) indicated in the procedural letter in the case of correspondence in administrative or civil matters;

3) contained in a publicly available source, e.g. publishing the address on a website, business card, etc.

In the first case, however, in practice, there are doubts as to whether each e-mail address indicated in the contract is an address that may be used for the exchange of correspondence intended to have a specific legal effect. In particular, it is about the situation where e-mail addresses are not indicated in the contract comparison, and in the part describing the method of its implementation, where these addresses are indicated as addresses of persons responsible for the contract. Failure to clearly indicate that these addresses can be used for this type of correspondence increases the legal uncertainty of the parties and significantly reduces the possibility of using electronic correspondence exchange to the indicated addresses as a way to achieve the expected legal effect. Summing up, the identification of the addressee and the legal effect of the correspondence exchange in this case are as strong as the sanction specified in mutual obligations for failure to notify about a change of e-mail address. The method of minimizing the indicated risks is to indicate specific e-mail addresses in the contract, which are used to exchange correspondence with legal consequences and to introduce sanctions for failure to notify about the change of such address. These sanctions usually take the following form:

1) ineffectiveness of the method of notification of the change of e-mail address, which was made in a manner other than that specified in the contract;

2) the effectiveness of delivery to the e-mail address in each case in which a formal notification of its change was not made in accordance with the content of the contract.

In the case of correspondence exchange carried out on the basis of e-mail addresses indicated in pleadings, the sanctions and legal effects of such an exchange are usually determined by law. The liability of the parties is limited to the correct verification of the address and to documenting the sending of the correspondence to the correct address. 
The method of exchanging correspondence to publicly available addresses is used only in the absence of another source of identification of the other party and its e-mail address. This method of exchanging communication raises high legal risks related to the validity of the address, proving its use by the other party and demonstrating the legal effectiveness of such exchange related to the obligation.

Legal provisions appear in the professional trade that increase the certainty of legal transactions through public e-mail addresses in appropriate open and accessible registers or publishers. An example of such a provision is the Polish register of entrepreneurs who are natural persons (CEIDG). The provisions regulating the operation of the register sometimes indicate that the entrepreneur may indicate his contact details, in particular e-mail address or contact details of the representative, in particular his e-mail address, website address, telephone number. Such publication of data in the public register increases the level of legal certainty in the case of correspondence exchanges conducted using this address, even if it is initiated only by one of the parties. The effectiveness of such an exchange will be determined in this respect by the scope of the power of attorney and procuration as well as the provisions of law regulating the principles of passive representation. ${ }^{3}$. A similar solution applies in the Register of Entrepreneurs atregulated by statute on the National Court Register. Entities on whose application an e-mail address has been entered into the register of entrepreneurs are required to report a change in this data. ${ }^{4}$

In recent years, solutions have emerged, based on generally applicable provisions of law, formalizing the horizontal exchange of correspondence between entities, including lawyers. Statutory solutions are introduced, followed by technical solutions to ensure an appropriate level of assurance of the addressee's identification, certainty of delivery and appropriate quality of evidence of information exchange. Thus, although this type of exchange is the domain of private law and the principle of party autonomy, nevertheless nation states, and sometimes corporations themselves, interfere with the indicated autonomy.

32018 Act on the Central Register and Information on Economic Activity and the Information Point for Entrepreneurs (Journal of Laws of 2020/ 2296).

41997 The National Court Register (Journal of Laws of 2021/ 112). 


\section{Hierarchical Exchange of Correspondence}

Hierarchical exchange of correspondence in the vast majority of cases is of a legal nature. This is one of the important elements distinguishing this type of exchange from horizontal exchange, where in most cases this exchange is factual and only for the selected type of correspondence does it have legal effects.

Hierarchical correspondence exchange, in contrast to horizontal exchange, is therefore highly formalized. Formalism manifests itself in two spheres: in the legal sphere, by strict regulation of the manner of carrying out the exchange of correspondence, which may have a legal effect, and in the case of electronic form, by specifying the tools by which it can be carried out.

The latter element is somewhat different from the correspondence carried out in paper form, where the main emphasis was not on the manner of delivery, but on specific evidence with which legal effects are associated, e.g. sending the parcel to an entity that could have issued a formal confirmation of posting. , e.g. by a postal operator, or at the time of service to a public entity or court, which left outside the scope of the regulation, the method of service and the entity that physically performed it.

In other words, in the electronic world, national states define what acts of service will be deemed to have legal effects and what tools the parties and representatives are obliged to use. Most often, these countries not only limit themselves to identifying these tools, but are also building them. These are all kinds of services online (electronic services). These are also dedicated portals where, apart from the correspondence exchange functionalities, other functionalities are also made available, such as access to files, participation in hearings, etc.). More on this in part VI, ch. 1.

The consequence of the failure to use the tool indicated by the Member State may be the legal ineffectiveness of the replacement. This ineffectiveness is not always absolute, because states allow the possibility of validating this ineffectiveness. There are, of course, different models; sometimes they allow the use of paper form within the deadline, although there is a noticeable trend of limiting this type of option for professional entities, including lawyers; sometimes it is possible to use the correct tool and the deadline is considered to be respected. There are procedures that do not, however, provide for the possibility of supplementing (validating) the activities, which in the case of tight deadlines poses a significant threat to the parties to the proceedings.

An example of such an absolute sanction of ineffectiveness is the submission of a pleading to the e-mail address of a public entity instead of 
its electronic inbox. ${ }^{5}$ - in the light of the Polish provision of the Code of Administrative Procedure. The second, now pan-European, example is the lack of use of electronic form for submitting a public procurement in a procedure where only the electronic way of submitting offers is provided. Failure to use the electronic route may not be validated in any way, even in the form of submitting a paper offer.

\section{Electronic Delivery - eIDAS Regulation}

A special type of correspondence exchange is Registered Electronic Delivery. It was regulated in the eIDAS Regulation. Registered Electronic Delivery is a trust service introduced at the European level. According to the eIDAS regulation we mean the trust service, namely the service realized by the entity called a trust service provider (TSP). TSP provides the service for remuneration, based on the adopted service policy and based on the adopted technical practice. The entire operation of such a provider is subject to trust service supervision. EU law gives you the freedom to provide trust services by allowing you to provide services in one country to entities in other EU countries.

Within the meaning of art. 3 of the eIDAS Regulation, the "electronic registered delivery service" means a service that makes it possible to transmit data between third parties by electronic means and provides evidence relating to the handling of the transmitted data, including proof of sending and receiving the data, and that protects transmitted data against the risk of loss, theft, damage or any unauthorised alterations. By means of the electronic delivery service, third parties exchange data (information) in a confidential and integrity-protected manner. The effect of the service is the issuance of proofs of sending and receiving data. The service provider is an independent entity that cannot be dependent on the sender or recipient (when carrying out delivery). An electronic delivery service may be provided by a single trust service provider, or it may enable delivery through the collaboration of multiple electronic delivery service providers. In such a situation, an item posted using one registered delivery service will be transferred between vendors so that the delivery is made via a vendor serving the addressee.

52011 The Regulation of the Prime Minister on the Preparation and Delivery of Electronic Documents and the Provision of Forms, Specimens and Copies of Electronic Documents (Journal of Laws of 2018/ 186). 
The eIDAS Regulation does not provide for equivalence between qualified electronic delivery services and traditional postal registered mail. However, it is indicated in the literature that Member States may establish this equivalence at national level ${ }^{6}$. This is also what happened in most regulations in Poland (as a result of the entry into force of the Act of November 18, 2020 on electronic delivery ${ }^{7}$ ), but also in Belgium and Denmark. Registered electronic delivery items are in principle equivalent to registered items where the provision so provides. However, the implementation of a hybrid shipment looks different, i.e. a shipment that takes a material form at any stage of delivery (sending or receiving). Polish law recognizes that a hybrid parcel is a type of postal item regulated under the provisions of postal law, while in Belgium it is assumed that it is a type of parcel qualified for the trust service ${ }^{8}$.

The basis for the definition of registered electronic delivery is the technological neutrality of the solution. The provisions of the eIDAS Regulation do not indicate which technology is to be used for electronic delivery. It only presents the mechanisms that must be provided for service to qualify as registered electronic delivery or qualified electronic delivery service. This allows for the adaptation of legal provisions to the current state of technology and applied solutions. An example is the possibility of exchanging correspondence by registered electronic delivery using the technology used in e-mail communication with additional requirements. For Qualified Registered Electronic Delivery the compliance with the ETSI EN 319521 standard (Security Requirements and Policies for Registered Electronic Delivery) confirms the fulfilment of legal requirements - a standard extending the requirements of ETSI EN 319401 with specific requirements for REM service providers.

Electronic delivery is a self-contained type of communication between entities and may take place independently of the services online. However, in the event of a binding of the service online it can complement such a service. In service online pre-defined electronic forms for the purpose of

6 Institut Luxembourgeois de la Normalisation, de l'Accréditation, de la Sécurité et qualité des produits et services, 'Trust Services Under the eIDAS Regulation' (Portail-qualite.lu, June 2018), <https://portail-qualite.public.lu/content/dam/qua lite/publications/confiance-numerique/trustservices-under-eIDAS.pdf $>$ access 19 February 2021.

7 J. of Laws, item 2320.

8 Mirko Faccioli in: Alessio Zaccaria, Martin Schmidt-Kessel, Reiner Schulze and Alberto M Gambino (eds) EU eIDAS Regulation. Commentary, (Beck/Hart 2020) 331. 
settling a given case may be created, or even advanced solutions based on authentication allowing for semi-automatic or fully automatic handling of the case. Electronic delivery then plays the role of a method of providing evidence of a transaction in the service (sending and receiving an application, settling the case). The value of such a solution is the fact that the evidence generated independently of the service itself, acts as if in the background of the main solution. The advantage of using electronic deliveries is that there is no need to build communication modules for users, the account management system in ICT systems providing services onlineand thus their faster construction and easier commissioning. Of course, in the case of complex processes, the construction of the indicated elements may be necessary, but with less advanced services online communication for such a service based on electronic delivery is sufficient.

\section{Qualified Electronic Delivery Service}

A qualified registered delivery service is a service provided by a qualified service provider, must meet the additional requirements of the eIDAS Regulation, as well as be subject to periodic audits and national supervision in the field of trust services. Data sent and received using a qualified electronic registered delivery service shall benefit from the presumption of data integrity, the sending of the data by the identified sender and receipt by the identified addressee, and the accuracy of the date and time of sending and receipt of the evidence indicated by the qualified electronic registered delivery service.

A qualified electronic delivery service provides identification of the sender and, prior to delivery, of the addressee. This identification ensures the safety of trading to the parties, protects them against unwanted correspondence and ensures the authenticity of the data provided. Identification in a qualified service may be performed on the basis of reliable nationally operating identification means, it may also be based on other mechanisms, in particular an electronic signature. The qualified electronic delivery service therefore combines the features of an advanced electronic signature and seal as well as a qualified time stamp?.

9 Łukasz Goździaszek (ed) Identyfikacja elektroniczna i ustugi zaufania w odniesieniu do transakcji elektronicznych na rynku wewnętrznym Unii Europejskiej. Komentarz (C. H. Beck 2020) 242. 
The provisions of Article 43 of the eIDAS Regulations assign legal effect to the evidence of the registered electronic delivery service, while there is no relevant regulation in the provisions on qualified electronic signature, including the indication that qualified electronic registered delivery, which is recognized in one country, will also be recognized in the other. The literature indicates that: "this is probably a mere oversight of the European legislator"10. It seems, however, that this is a deliberate action, because unlike qualified electronic signatures, qualified electronic seals or qualified time stamps, it is necessary to build an appropriate infrastructure for the exchange of information under this trust service. The services indicated above may operate in either mode offline or they can be used in any available communication technology, e.g. e-mail. In this case, registered electronic delivery requires the construction of similar technical solutions as in the case of electronic identification.

The specificity of qualified electronic delivery is an appropriately organized model of identification of entities participating in the transmission of correspondence, and then the delivery mechanism. Delivery in a qualified service is normally carried out with the following steps:

1) the sender identifies and authenticates to the delivery service and then forwards the data (parcel);

2) after receiving the data, the service issues a proof of posting and marks it with a qualified time stamp;

3) the data is forwarded to the service provider who will deliver it to the addressee;

4) the addressee is informed about the waiting data;

5) the addressee identifies and authenticates to the service, and then the service makes the item available to the addressee;

6) the service issues a proof of receipt and marks it with a qualified time stamp.

The described requirements as to the certainty of the process of identifying the parties to the correspondence exchange, the method of securing it and generating evidence affect, from the technical side, the high probability of establishing the course of correspondence. For this reason, the European legislator, as with other trust services, decided to grant additional legal presumptions to qualified electronic services.

10 Zaccaria, Schmidt-Kessel, Schulze and Gambino (n 8) 327. 


\section{Polish Act on Electronic Delivery}

\subsection{Introduction}

The act on electronic delivery lays down rules for the delivery of electronic documents whose addressee or sender is the public administration. Delivery, in accordance with DorElektrU, is carried out using a public service and qualified electronic registered delivery services. As part of DorElektrU, the role of a service supporting public entities directly will be played by a public service provider - a designated operator, which will perform all activities based on the same requirements that apply to qualified suppliers. Individuals and private entities will be able to choose whether they will be served by a public registered delivery service or a qualified service. Qualified suppliers will be able to service individuals and private entities, providing them with the possibility of sending correspondence to other private entities, as well as to public administration. In the field of handling parcels addressed to public administration, qualified services will exchange data with the public electronic delivery service.

\subsection{Common Address Infrastructure}

An interesting solution chosen by the Polish legislator is the introduction of a common address infrastructure for all providers of registered electronic delivery (including qualified delivery) who wish to join the system. Effective service requires the possibility of indicating the addressee or addressees of a given registered electronic delivery. According to DorElektrU, the address for electronic deliveries given by the minister responsible for computerization will be used to uniquely identify the addressee of parcels. This address will be assigned to the service that directly serves the addressee, while the database of electronic addresses will enable the address to be verified and the shipment to be properly directed to the supplier who supports it. To ensure the unambiguous assignment of a natural, legal or public entity to an address, this address will be unique and once assigned to one entity it cannot be assigned to another. In addition, public entities will be able to search for the address itself on the basis of other characteristics of the addressee's identity, e.g. name, surname, PESEL number and physical address. This is a solution that has not been provided for directly in the eIDAS Regulation. However, its introduction has a practical dimension, which is the introduction of an address management 
mechanism so that any changes to service providers do not affect changes in addresses.

\subsection{Reception and Mailing Boxes}

The electronic registered delivery service does not require sending and delivery to be made from dedicated boxes, lockers or named infrastructure. In particular, the party sending the document may use the electronic delivery service, without the need to have any account in a given service. In the case of a qualified service, delivery should, however, be preceded by the identification of the sender. The electronic service itself also does not have to be performed only for the person who has previously registered in the service, and the condition for submitting the document is the identification of the person who is the addressee of the document; DorElektrU also points out that deliveries by means of the public registered delivery service will be carried out using a delivery box, which will allow for the temporary storage of the correspondence delivered and the proof of posting and receipt.

\subsection{Mandatory Address for the Legal Profession}

The Polish regulation introduces the obligation for selected legal professions to have an address for electronic delivery and to report it to the register referred to in Chapter 7.2. The indicated obligation was included not only in DorElektrU, but also in acts regulating the manner of performing a given legal profession (legal advisers and advocates). Thus, this obligation is not only an administrative and legal obligation, but is an element of a professional obligation, and failure to comply with it may constitute grounds for disciplinary liability. A legal practitioner will be able to choose the provider of his e-mail address. The attorney-at-law will be able to choose either the address at the designated operator and in this case will receive an electronic delivery box or will be able to use the service of a qualified electronic delivery provider, i.e. a private entity, which will be entitled to provide such a service. The electronic delivery address will be able to be used for both hierarchical and horizontal communication. 


\section{Qualified Electronic Delivery in Selected EU Member States}

At the time of writing, there were 19 qualified electronic registered delivery service providers in the EU. Most qualified services are provided in France ( 7 services) and Spain ( 5 services). Detailed analysis shows that they are used in the field of business transactions, in particular for processes such as signing contracts and sending invoices. In these services, most often the addressee does not have to have an account or a distinguished address for electronic delivery, and the delivery is made to a natural or legal person defined by the sender, which additionally defines the method of notifying the addressee about the pending shipment, e.g. via his address e-mail. An interesting conclusion from the analysis of these services is the fact that while the level of verification of the sender's identity is verified in detail, in many implementations the level of verification of the addressee's identity is carried out in accordance with the sender's guidelines - i.e. in some situations only based on e-authentication. e-mail.

Due to the introduced solutions, on the basis of the EU, we can distinguish different models of the organization of the system for ensuring registered electronic delivery. The cooperation model, in which the state provides electronic delivery services through a designated operator, is used in the Czech Republic, Belgium, Denmark and France. The e-delivery service, which includes, inter alia, hybrid shipment, is provided, inter alia, in France ${ }^{111213}$ (in Czech Republic, the hybrid service provides for both the processing of digital information into traditional mail and the digitization of an analog mail).

An interesting model is also the Italian solution. The Italian e-delivery model is currently the most developed in the EU. Italian Certified Electronic Mail (Italian La Posta Elettronica Certificata, PEC $\left.{ }^{14}\right)$. The functioning of the PEC is based on a dozen commercial PEC service providers who complete the delivery process and issue the appropriate shipping and receipt receipts. As part of the system's operation, the Public Administration

112016 Act on the Digital Republic (LOI n ${ }^{\circ}$ 2016-1321) <https://www.legifrance.go uv.fr/jorf/id/JORFTEXT000033202746> accessed 25 March 2021.

122008 Czech Act No. 300/2008 col. on Electronic Measures and Authorized Document Conversion (Zákon č. 300/2008). https://www.zakonyprolidi.cz/cs/2008-300.

13 Regulation (EU) 910/2014 of The European Parliament and of the Council of 23 July 2014 on Electronic Identification and Trust Services for Electronic Transactions in the Internal Market and Repealing Directive 1999/93/EC L 257/73

142005 Digital Administration Code (Codice dell'Administrazione Digitale, Decreto Legislativo 82/2005 modificato ed integrato dal Decreto Legislativo 235/2010). 
Index has been made available, which allows you to check and use PEC addresses of any public entity. Each public entity is required to create a PEC box as part of the services of one of the suppliers and forward this address to the market surveillance unit (Agency for Digital Italy - AgID). Electronic transmission of information requiring collection is carried out on the basis of the decree of the President of the Republic of February 11, 2005. ${ }^{15}$ Pursuant to this act, the electronic transmission of an electronic document is tantamount to notification by post, unless the law provides otherwise. In 2020, as part of the PEC operation, over 2 billion electronic parcels were sent, there were over 12 million registered mailboxes and over 250,000 domains.

Registered electronic delivery is a service which, due to its conditions, is still at the implementation stage, as opposed to, for example, electronic signatures. Although the number of entities providing this service is small compared to other trust services, the number of such solutions is slowly growing. For example, in February 2021, in Bulgaria was launched the first one qualified electronic registered delivery service ${ }^{16}$, this service carries out the process of electronic delivery based on the portal and mobile phone applications. As part of the indicated service, it is possible to deliver electronic parcels to and from public administration, also in accordance with the information provided on the website of the court parcel service provider.

As shown by the experiences of various EU Member States, electronic service requires changes to the national law in order to fully implement it. Although the presumptions related to the use of qualified electronic registered delivery ensure legal certainty, the full implementation of solutions is hampered by specific procedures that exist in the Member States. It should be remembered that one of the principles of EU law is the procedural autonomy of the Member States, which means that this area of law is still largely regulated in a national and traditional manner, i.e. in paper form. The full implementation of registered service therefore requires changes to the provisions of national law. It generally takes place in two ways. The first is the introduction of a single legal act indicating a possible way of communication between businesses and citizens, and between

152005 Decree of the President of the Republic of February 11 (Decreto del Presidente della Repubblica 11 febbraio 2005 No. 68).

16 See Evrotrust, 'Sending and receiving courts' decisions is already possible through the smartphone' (www.evrotrust.com, 9 February 2021) <https://www.evrotrust.c $\mathrm{om} /$ landing/en/a/sending-and-receiving-courts-decisions-is-already-possible-throug h-the-smartphone> access 19 February 2021. 
citizens and public authorities. The second model is making changes to specific procedures. For example, in the Republic of Poland, in order to ensure the actual implementation of a registered electronic delivery, approx. 160 different legal acts, including KPA and court procedures. The second problem with the use of electronic delivery is the reconciliation of this trust service with postal services. As indicated above, the European legislator did not comment on the relationship between the eIDAS Regulation and Directive 97/67 / EC of the European Parliament and of the Council of December 15, 1997 on common rules for the development of the internal market of Community postal services and the improvement of the quality of services. ${ }^{17}$. the Journal of Law, the EU, the Polish Special Edition, chapter 6 , vol. 3, p. 71, as amended), assuming that these two regulations differ from each other and function independently of each other. However, the practice of economic trading shows that these ranges intersect in at least two places. The first scope is the already indicated equation of paper correspondence and correspondence carried out on the basis of registered electronic delivery in the light of national law. The second scope is the qualification of the hybrid service as either a postal service or a trust service. As shown by the experiences of the Member States, the practice of regulating the above-mentioned the scope varies.

\section{The PEPPOL System - Description of the Solution Today and Development Prospects}

In addition to qualified and public registered electronic delivery services, there is also a PEPPOL system in the EU consisting of many registered but unqualified delivery services cooperating within one network. These services, after meeting the criteria imposed within the network, in particular after meeting the communication standard and common address infrastructure, serve delivery nodes. The PEPPOL network is used for communication between business entities in the field of the transmission of invoices and business documents. Pursuant to the regulations in force in the Republic of Poland, invoicing for large public procurement procedures takes place via the PEPPOL network. The experience from building the PEPPOL network was used to define the requirements for qualified delivery services and to build mechanisms that will function within public deliveries in the Republic of Poland. Currently, the PEPPOL system is

17 OJ WE L 1998 No. 15, 4 as amended. 
directed and focused on the elements of trade exchange within orders and e-invoicing. However, due to the fact that countries not only from the EU region are starting to operate in the PEPPOL network, but also, for example, from Australia, Singapore, and through these countries other Asian countries ${ }^{18}$, there is a great potential for using the PEPPOL network to create an exchange standard in the future, not only of commercial but also legal documents. The advantage of the PEPPOL network over the electronic delivery solutions defined today in the ETSI standards is its open standard (based on opensource) and by the practice of applying in cross-border trade. The experience in ensuring interoperability in various legal systems may prove to be invaluable and significantly influence the increasing use of the standard on a global scale.

18 OpenPEPPOL AISBL, 'Nationwide E-Invoicing Framework in Singapore' (Peppol.eu) <https://peppol.eu/what-is-peppol/peppol-country-profiles/singapore-coun try-profile/> access 19 February 2021. 
